\title{
Emergency medical services use and its association with acute ischaemic stroke evaluation and treatment in Singapore
}

\author{
Hanzhang Xu (D) , 1,2 Ying Xian,, ${ }^{3,4}$ Fung Peng Woon, ${ }^{5}$ Janet Prvu Bettger, ${ }^{3,6}$ \\ Daniel T Laskowitz, ${ }^{3,4}$ Yih Yng Ng, ${ }^{7}$ Marcus Eng Hock Ong, ${ }^{8,9}$ \\ David Bruce Matchar, ${ }^{9,10}$ Deidre Anne De Silva ${ }^{5}$
}

To cite: Xu H, Xian Y, Woon FP, et al. Emergency medical services use and its association with acute ischaemic stroke evaluation and treatment in Singapore. Stroke \& Vascular Neurology 2020;5: e000277. doi:10.1136/svn-2019-000277

Received 30 August 2019 Revised 17 March 2020 Accepted 27 March 2020 Published Online First 8 April 2020

\section{Check for updates}

(c) Author(s) (or their employer(s)) 2020. Re-use permitted under CC BY-NC. No commercial re-use. See rights and permissions. Published by BMJ.

For numbered affiliations see end of article.

Correspondence to Hanzhang Xu; hanzhang.xu@duke.edu

\section{ABSTRACT}

Background Emergency medical services (EMS) is a critical link in the chain of stroke survival. We aimed to assess EMS use for stroke in Singapore, identify characteristics associated with EMS use and the association of EMS use with stroke evaluation and treatment.

Methods The Singapore Stroke Registry combines nationwide EMS and public hospital data for stroke cases in Singapore. Multivariate regressions with the generalised estimating equations were performed to examine the association between EMS use and timely stroke evaluation and treatment.

Results of 3555 acute ischaemic patients with symptom onset within 24 hours admitted to all five public hospitals between 2015 and 2016, 68\% arrived via EMS. Patients who used EMS were older, were less likely to be female, had higher stroke severity by National Institute of Health Stroke Scale and had a higher prevalence of atrial fibrillation or peripheral arterial disease. Patients transported by EMS were more likely to receive rapid evaluation (door-to-imaging time $\leq 25 \mathrm{~min} 34.3 \%$ vs $11.1 \%$, $\mathrm{OR}=2.74(95 \% \mathrm{Cl} 1.40$ to 5.38)) and were more likely to receive intravenous tissue plasminogen activator (tPA, $22.8 \%$ vs $4.6 \%, 0 \mathrm{R}=4.61(95 \% \mathrm{Cl} 3.52$ to 6.03$)$ ). Among patients treated with IPA, patients who arrived via EMS were more likely to receive timely treatment than selftransported patients (door-to-needle time $\leq 60 \mathrm{~min} 52.6 \%$ vs $29.4 \%, \mathrm{OR}=2.58(95 \% \mathrm{Cl} 1.35$ to 4.92$))$.

Conclusions EMS use is associated with timely stroke evaluation and treatment in Singapore. Seamless EMSHospital stroke pathways and targeted public campaigns to advocate for appropriate EMS use have the potential to improve acute stroke care.

\section{INTRODUCTION}

Stroke is the fourth leading cause of morbidity and mortality in Singapore. ${ }^{2}$ Despite numerous clinical trials demonstrating the effectiveness of thrombolytic therapy for improving outcomes in acute ischaemic stroke, ${ }^{3}{ }^{4}$ utilisation of tissue plasminogen activator (tPA) has been lower in Singapore than in western countries such as the USA, suggesting further room for improvement. ${ }^{56}$ Even among those treated, only half received thrombolytic therapy within $60 \mathrm{~min} .{ }^{78}$ Several studies have demonstrated that the use of emergency medical services (EMS) is associated with rapid evaluation and treatment of stroke. ${ }^{6-11}$ However, most of these studies were conducted in western countries such as the USA. Less is known about EMS use among stroke patients in Asian-Pacific countries such as Singapore where the cultures, healthcare and EMS systems are different from western countries. $^{12} 13$ A previous nationwide study in Singapore showed that nearly half of the patients with ST-segment elevation myocardial infarction came to the hospital using private transportation modes. ${ }^{14}$ Regional studies also found that EMS is underutilised for only $50 \%$ stroke patients in Singapore arrived at hospitals via EMS,${ }^{58}$ despite it being a universal service which is free for emergency calls. Identifying factors associated with EMS use will provide critical information needed to inform the design of tailored interventions to increase public stroke awareness and promote actions that will lead to early hospital arrival and treatment.

Using national data, we aimed to identify characteristics associated with EMS use in stroke patients and examine the association of EMS use with timely stroke evaluation and treatment. We hypothesise that EMS use is associated with timely in-hospital stroke care in Singapore.

\section{METHODS}

\section{Setting and data sources}

Singapore is an urban city-state and island country that has the world's third highest population density. ${ }^{15} 16$ Unlike the EMS systems in western countries such as the USA where the structure of EMS varies by state, EMS in Singapore is a single-tier, fire department-based system. ${ }^{17} 18$ Run by the Singapore Civil Defence Force (SCDF), this national EMS system responds to any medical emergencies on the island and is 
free to all callers. ${ }^{17}$ Specifically, the EMS is activated by a centralised 995 dispatching system and the ambulances are manned by three crew members including an intermediate level emergency medical technician (EMT), a basic level EMT and a driver. ${ }^{17}$ Ambulance crews are trained to perform prehospital stroke assessment using the Cincinnati Prehospital Stroke Scale (CPSS) ${ }^{19}$ and transport suspected stroke patients to designated public hospitals that are approved to deliver acute stroke care. ${ }^{17}$

For this retrospective study, we extracted anonymised data related to EMS use among stroke patients from the Singapore Stroke Registry, a national stroke registry that was developed to collect and analyse epidemiological and clinical data on all stroke cases among Singapore residents aged 15 years and above who were admitted to all the public hospitals in Singapore.$^{20}$ The registry consists of several data sources: medical claims (ie, MediClaims) from the Ministry of Health, hospital inpatient discharge summary from all public healthcare institutions and data from the Death Registry. Stroke cases were identified based on International Classification of Diseases-Ninth and Tenth Revision clinical modification. The National Registry Disease Office (NRDO) collected and extracted relevant information on patient demographic characteristics, medical history, inpatient evaluation, treatment, events, discharge deposition and mortality. The institutional review board and NRDO approved all study procedures.

\section{Study population}

Using Singapore Stroke Registry data, we included all acute ischaemic stroke patients aged 18 or older who arrived to one of the five public hospitals between 1 January 2015 and 31 December $2016(\mathrm{n}=11952)$. We excluded patients with no documented time of symptom onset $(n=5484)$, in-hospital strokes $(n=597)$, transferred from another hospital $(\mathrm{n}=360)$, onset-to-door time greater than 24 hours $(n=743)$ or those with missing information on mode of transportation to the hospital $(n=1204)$. The final cohort consisted of 3555 patients. Among these patients, 600 of them received tPA treatment.

\section{Variable of interest and process of care measures}

We defined EMS use as patients who arrived at the hospital by SCDF ambulance; whereas we considered those who arrived via other transportation modes (eg, taxi, subway or private cars) as self-transported patients. Process of care measures included door-to-imaging time (continuous, \% of door-to-imaging time $\leq 25 \mathrm{~min}$ ), doorto-needle time (continuous, $\%$ of door-to-needle time $\leq 60 \mathrm{~min})$ and treatment rate of intravenous tPA in all eligible ischaemic stroke patients. We also assessed the proportion of patients who arrived within 2 hours after symptom onset and were treated within 3 hours (arrival by 2 hours and treated by 3 hours) and arrival by 3.5 hours and treated by 4.5 hours.

\section{Statistical analyses}

We first described the demographic and clinical characteristics by mode of transportation to the hospital in all eligible patients and in a subgroup of patients who arrived within 3.5 hours of symptom onset. We used median and interquartile range (IQR) for continuous variables and used frequencies and percentages for categorical variables. We applied $\chi^{2}$ and Wilcoxon rank-sum tests as appropriate to compare the differences in characteristics between patients who arrived via EMS and those who self-transported. Next, we identified the demographic and clinical characteristics associated with EMS use in all patients and in patients with onset to arrival within 3.5 hours (potentially eligible for the 4.5 hours treatment window) by using logistic regression models with the generalised estimating equations (GEE) that accounted for within-hospital clustering. We applied stepwise-selection methods to identify the key factors significantly associated ( $p$ value $<0.05$ ) with EMS use. We further applied a set of linear and logistic regression models with the GEE to examine how EMS use was associated with process of care measures including doorto-imaging time, tPA treatment rate and door-to-needle time. These analyses accounted for a variety of patient demographic and clinical characteristics, including age, sex, ethnicity (Chinese, Malay, Indian or others), medical history (transient ischaemic attack (TIA), stroke, hypertension, diabetes mellitus, ischaemic heart disease, atrial fibrillation, valvular heart disease, peripheral arterial disease, hyperlipidaemia and smoking status), National Institute of Health Stroke Scale (NIHSS, 0-4, 5-15, 16+, unknown) and office-hour presentation (stroke patients presenting to the emergency department between 7:00 am and 6:00 pm on any weekdays). In the final multivariate models, we examined a series of indices including variance inflation factors, tolerance and condition values and identified no possible multicollinearity and overidentification. All statistical tests were two-tailed and considered statistically significant at $p<0.05$. All statistical analyses were performed using SAS V.9.3 software.

\section{RESULTS}

Baseline characteristics and factors associated with EMS use

Table 1 displays the characteristics of our study population. Overall, the median age of patients was 69 (IQR: $60-79)$ and $41.7 \%$ were female. A total of 2417 acute ischaemic patients were transferred to the hospital by EMS, accounting for $68 \%$ of the entire cohort. Compared with self-transported patients, patients who arrived via EMS were older, more likely to be female, had a history of hypertension, ischaemic heart disease, or atrial fibrillation, and had more severe stroke by NIHSS (median NIHSS 8 vs 3). Similar characteristics were found in the subgroup of those who arrived within 3.5 hours of symptom onset (59.7\% of the study population, table 2). After risk adjustment, older age (per 5year increase, $\mathrm{OR}=1.06(95 \%$ CI 1.04 to 1.09$))$, female sex $(\mathrm{OR}=0.87$ 
Table 1 Characteristics of all patients arrived within 24 hours by emergency medical services use

\begin{tabular}{|c|c|c|c|c|}
\hline \multirow[b]{2}{*}{ Patient characteristics } & \multirow{2}{*}{$\begin{array}{l}\text { Overall }(n=3555) \\
N(\%)\end{array}$} & \multirow{2}{*}{$\begin{array}{l}\text { EMS }(n=2417) \\
N(\%)\end{array}$} & \multirow{2}{*}{$\begin{array}{l}\text { No EMS }(\mathrm{n}=1138) \\
\mathrm{N}(\%)\end{array}$} & \multirow[b]{2}{*}{$P$ value } \\
\hline & & & & \\
\hline Age, median (IQR) & $69(60-79)$ & $71(61-81)$ & $66(57-76)$ & $<0.001$ \\
\hline \multicolumn{5}{|l|}{ Ethnicity } \\
\hline Chinese & $2680(75.4)$ & $1811(74.9)$ & $869(76.4)$ & 0.08 \\
\hline Others & $66(1.9)$ & $37(1.5)$ & $29(2.5)$ & \\
\hline \multicolumn{5}{|l|}{ Medical history } \\
\hline TIA & $168(4.7)$ & $114(4.7)$ & $54(4.7)$ & 0.97 \\
\hline Stroke & 849 (23.9) & $589(24.4)$ & $260(22.8)$ & 0.32 \\
\hline Atrial fibrillation & 687 (19.3) & $562(23.3)$ & $125(11.0)$ & $<0.001$ \\
\hline Valvular heart disease & $98(2.8)$ & $72(3.0)$ & $26(2.3)$ & 0.24 \\
\hline Peripheral arterial disease & $107(3.0)$ & $79(3.3$ & $28(2.5)$ & 0.19 \\
\hline Hyperlipidaemia & $3217(90.5)$ & $2174(89.9)$ & $1043(91.7)$ & 0.11 \\
\hline \multicolumn{5}{|l|}{ Smoking status* } \\
\hline Never & $2106(60.1)$ & $1450(61.1)$ & $656(58.0)$ & 0.13 \\
\hline Former smoker & $502(14.3)$ & $340(14.3)$ & $162(14.3)$ & \\
\hline Current smoker & $897(25.6)$ & $584(24.6)$ & $313(27.7)$ & \\
\hline Office-hour arrival† & $1638(46.0)$ & $1098(45.4)$ & $540(47.5)$ & 0.23 \\
\hline Unknown & $618(17.4)$ & $445(18.4)$ & $173(15.2)$ & \\
\hline
\end{tabular}

*50 missing values in smoking status, 618 missing values in NIHSS.

†Office-hour arrival: weekdays 7 am to $6 \mathrm{pm}$.

EMS, emergency medical services; NIHSS, National Institutes of Health Stroke Scale; TIA, transient ischaemic attack.

(95\% CI 0.79 to 0.97$)$ ), medical history of atrial fibrillation $(\mathrm{OR}=1.71(95 \%$ CI 1.37 to 2.14$))$ or peripheral arterial disease $(\mathrm{OR}=1.29$ (95\% CI 1.02 to 1.64$)$ ), and more severe stroke (NIHSS $5-15$ vs $0-4$; OR=2.39 (95\% CI 1.89 to 3.02 ); NIHSS $16+v s$ $0-4$; OR=9.53 (95\% CI 3.35 to 27.13); NIHSS unknown vs $0-4$; OR=1.69 (95\% CI 1.23 to 2.33)) were associated with a greater likelihood of EMS use (table 3). A similar set of results were found among patients who arrived within 3.5 hours of symptom onset, with the exception of female sex (table 3 ).

\section{Association between EMS use and stroke evaluation and} treatment

Overall, $17.0 \%$ of stroke patients received tPA treatment. We observed differences in the timing of evaluation, the proportion of patients treated with $\mathrm{TPA}$, and timing of tPA treatment between patients arriving by EMS and self-transported individuals (table 4). After adjusting for demographic and clinical characteristics, EMS use was associated with shorter door-to-imaging time (adjusted mean difference, $-74 \min (95 \% \mathrm{CI}-92$ to -56$)$ ), and more patients with door-to-imaging time within $25 \mathrm{~min}$ ( $34.3 \%$ vs $11.1 \%, \mathrm{OR}=2.74$ (95\% CI 1.40 to 5.38$)$ ). In addition, among those who arrived within 2 hours of symptom onset, patients transported by EMS were more likely to receive tPA within 3 hours $(33.1 \%$ vs $13.9 \%$, $\mathrm{OR}=2.25$ (95\% CI 1.92 to 2.62)). Similar findings for EMS use on tPA treatment rate were observed in patients with symptom onset within 3 hours and treated within 4.5 hours $(31.8 \%$ vs $11.7 \%$, OR $=2.55$ (95\% CI 2.10 to 3.10)). Furthermore, among tPA-treated patients, those transported by EMS had significantly shorter door-toneedle time (adjusted mean difference, -11 min (95\% CI 
Table 2 Characteristics of all patients arrived within 3.5 hours by emergency medical services use

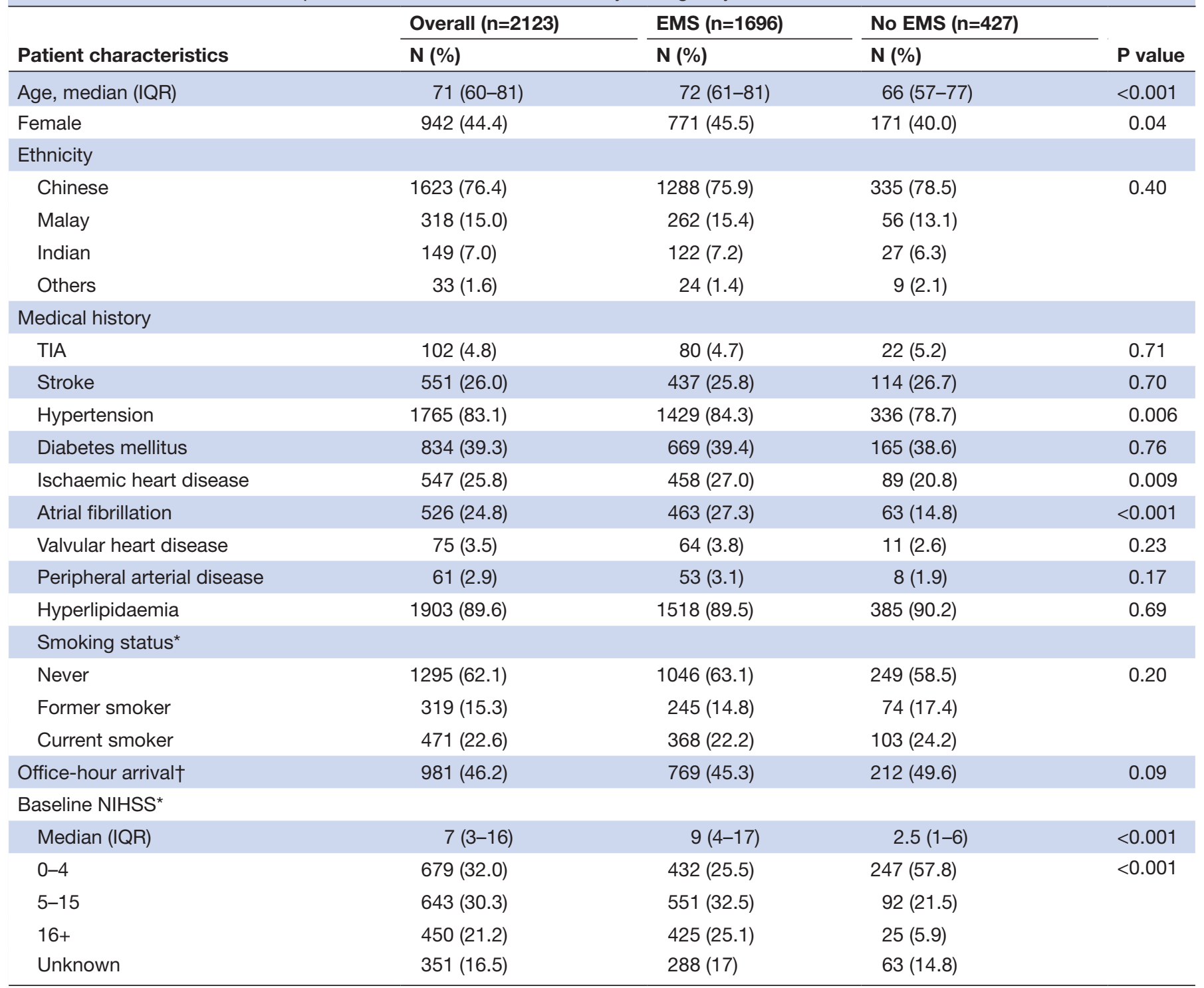

*41 missing values in smoking status, 351 missing values in NIHSS.

†Office-hour arrival: weekdays 7 am to $6 \mathrm{pm}$.

EMS, emergency medical services; NIHSS, National Institutes of Health Stroke Scale; TIA, transient ischaemic attack.

-19 to -3$)$, figure 1) and were also more likely to receive timely treatment (door-to-needle time $\leq 60 \mathrm{~min}$ ) than selftransported patients $(52.6 \%$ vs $29.4 \%$, OR $=2.58(95 \%$ CI 1.35 to 4.92$)$ ).

\section{DISCUSSION}

To the best of our knowledge, our study is among the first to investigate the use of EMS in a national provided system and its association with stroke evaluation and treatment in Asia-Pacific countries. Using data from the Singapore Stroke Registry that integrated several data sources, we found that still nearly one-third of acute ischaemic stroke patients were not transported to the hospital via EMS. Patients transported by EMS were more likely to receive more rapid evaluation and treatment than selftransported patients.
In our study, although the proportion of individuals transported by EMS is higher than in previous studies, ${ }^{58}$ still one-third of our stroke patients arrived to the hospital via private vehicles or taxis. A 2014 population-based study in Singapore reports that more than half of the participants could not recognise any of the FAST symptoms (facial droop, arm weakness and speech difficulty), and over $40 \%$ did not know the correct number for EMS, despite the availability of 995 universal access number for Fire and EMS. ${ }^{21}$ In addition, results from our multivariate analyses also suggest that age was the only significant demographic factor that was associated with EMS use among patients who arrived within 24 hours of symptom onset and among those who arrived within 3.5 hours. Therefore, it is likely that the EMS use is largely driven by recognition of stroke symptoms. The share of 
Table 3 Factors associated with EMS use for patients arrived within 24 hours and patients arrived within 3.5 hours

\begin{tabular}{|c|c|c|c|c|}
\hline Variables & $\begin{array}{l}\text { Arrival by } 24 \text { hours }(n=3555) \text {, OR } \\
(95 \% \mathrm{Cl})\end{array}$ & $P$ value & $\begin{array}{l}\text { Arrival by } 3.5 \text { hours }(n=2123) \text {, OR } \\
(95 \% \mathrm{Cl})\end{array}$ & $P$ value \\
\hline Age (per 5 year increase) & $1.06(1.04-1.09)$ & $<0.001$ & $1.05(1.02-1.08)$ & $<0.001$ \\
\hline Atrial fibrillation & $1.71(1.37-2.14)$ & $<0.001$ & $1.56(1.33-1.82)$ & $<0.001$ \\
\hline Peripheral arterial disease & $1.29(1.02-1.64)$ & 0.03 & $1.58(1.16-2.16)$ & 0.004 \\
\hline $16+$ & 9.53 (3.35-27.13) & $<0.001$ & 7.53 (4.64-12.19) & $<0.001$ \\
\hline Unknown & $1.69(1.23-2.33)$ & 0.001 & $1.85(1.45-2.27)$ & $<0.001$ \\
\hline
\end{tabular}

$P$ values are based on logistic regressions with the generalised estimating equations, and logistic regressions with the generalised estimating equations after stepwise selection for adjusted OR.

EMS, emergency medical services; NIHSS, National Institutes of Health Stroke Scale.

stroke patients who failed to use EMS remains a concern, suggesting missed opportunities to increase public awareness of stroke signs and symptoms and the importance of EMS use when recognising symptoms suggestive of stroke. In Singapore, there have been national-level stroke awareness campaigns in Singapore annually from October 2016, emphasising stroke symptoms recognition and use of ambulance service as a call to action. ${ }^{22}$ Future research is planned to evaluate the impact of national campaigns on stroke symptom recognition, sensitivity and specificity of stroke identification, temporal trends in EMS use among stroke patients and timely tPA treatment rate.

Similar to prior studies conducted in other countries, ${ }^{6} 112324$ we found that stroke patients with more comorbidities and more severe stroke were more likely to utilise EMS. These findings are also comparable to the results from a recent study in Singapore that more severe onset symptoms was associated with higher likelihood of EMS use among patients experiencing myocardial infarction. ${ }^{25}$ However, in line with prior research, ${ }^{623}$ our results suggest that having a previous history of stroke or TIA did not impact a patient's likelihood of using EMS in a subsequent stroke event. Stroke patients are at a greater risk for another attack and the recurrent event is often more severe and debilitating. ${ }^{26-28}$ Therefore, preventing and promptly treating subsequent stroke events is critical for improving the functional and health outcomes in stroke patients. Although the current guide for stroke survivors in Singapore included information on immediate actions for a second stroke, the implementation and effectiveness of this aspect of stroke education in clinical practice

\begin{tabular}{|c|c|c|c|c|c|c|}
\hline & EMS & No EMS & Unadjusted OR (95\% Cl) & $P$ value & Adjusted OR* $(95 \% \mathrm{Cl})$ & $P$ value \\
\hline \multicolumn{7}{|l|}{ Overall $(n=3555)$} \\
\hline $\begin{array}{l}\text { Door to imaging time in min, } \\
\text { mean (SD) }\end{array}$ & $91(254)$ & $165(272)$ & $-74(-92$ to -56$) \dagger$ & $<0.001$ & $-58(-74$ to -42$) \ddagger$ & $<0.001$ \\
\hline Door to imaging time $\leq 25 \mathrm{~min}$ & $829 / 2417(34.3 \%)$ & 126/1137 (11.1\%) & 4.19 (3.42 to 5.13$)$ & $<0.001$ & 2.74 (1.40 to 5.38$)$ & 0.003 \\
\hline tPA treatment rate & $552 / 2417(22.8 \%)$ & $52 / 1138(4.6 \%)$ & $6.18(4.61$ to 8.29$)$ & $<0.001$ & 4.61 (3.52 to 6.03 ) & $<0.001$ \\
\hline $\begin{array}{l}\text { tPA arrival by } 2 \text { hours and } \\
\text { treatment by } 3 \text { hours }\end{array}$ & $444 / 1343(33.1 \%)$ & $34 / 244(13.9 \%)$ & 3.05 (2.09 to 4.46$)$ & $<0.001$ & 2.25 (1.92 to 2.62$)$ & $<0.001$ \\
\hline $\begin{array}{l}\text { tPA arrival by } 3.5 \text { hours and } \\
\text { treatment by } 4.5 \text { hours }\end{array}$ & $539 / 1696(31.8 \%)$ & $50 / 427(11.7 \%)$ & 3.51 (2.57 to 4.80$)$ & $<0.001$ & 2.55 (2.10 to 3.10$)$ & $<0.001$ \\
\hline \multicolumn{7}{|c|}{ Among patients received tPA $(n=600)$} \\
\hline $\begin{array}{l}\text { Door to imaging time in min, } \\
\text { mean (SD) }\end{array}$ & $26(16)$ & $35(16)$ & $-9(-13$ to -4$) \dagger$ & $<0.001$ & $-8(-13$ to -4$) \ddagger$ & $<0.001$ \\
\hline Door to imaging time $\leq 25 \mathrm{~min}$ & $282 / 549(51.4 \%)$ & $15 / 51(29.4 \%)$ & 2.53 (1.36 to 4.74$)$ & 0.003 & 2.51 (1.38 to 4.58$)$ & 0.002 \\
\hline DTN in min, mean (SD) & $66(28)$ & $77(27)$ & $-11(-19$ to -3$) \dagger$ & 0.008 & $-11(-19$ to -3$) \ddagger$ & 0.006 \\
\hline $\mathrm{DTN} \leq 60 \mathrm{~min}$ & $289 / 549(52.6 \%)$ & $15 / 51(29.4 \%)$ & 2.67 (1.43 to 4.98$)$ & 0.002 & 2.58 (1.35 to 4.92$)$ & 0.004 \\
\hline $\mathrm{DTN} \leq 45 \mathrm{~min}$ & $127 / 549(23.1 \%)$ & $2 / 51$ (3.9\%) & 7.37 (1.77 to 30.7$)$ & 0.006 & 8.03 (1.63 to 39.5$)$ & 0.01 \\
\hline
\end{tabular}

P values are based on logistics regression models with the generalised estimating equations for adjusted OR, and linear regression models with the generalised estimating equations for adjusted mean differences.

${ }^{*}$ Adjusted for age, sex, ethnic group, previous stroke/TIA, history of hypertension, diabetes mellitus, ischaemic heart disease, atrial fibrillation/flutter, valvular heart disease, peripheral arterial disease, hyperlipidaemia, smoker, Office-hour arrival and National Institutes of Health Stroke Scale (NIHSS).

tUnadjusted mean differences.

$\ddagger$ Adjusted mean differences.

DTN, door to needle; EMS, emergency medical services; TIA, transient ischaemic attack; tPA, tissue plasminogen activator. 


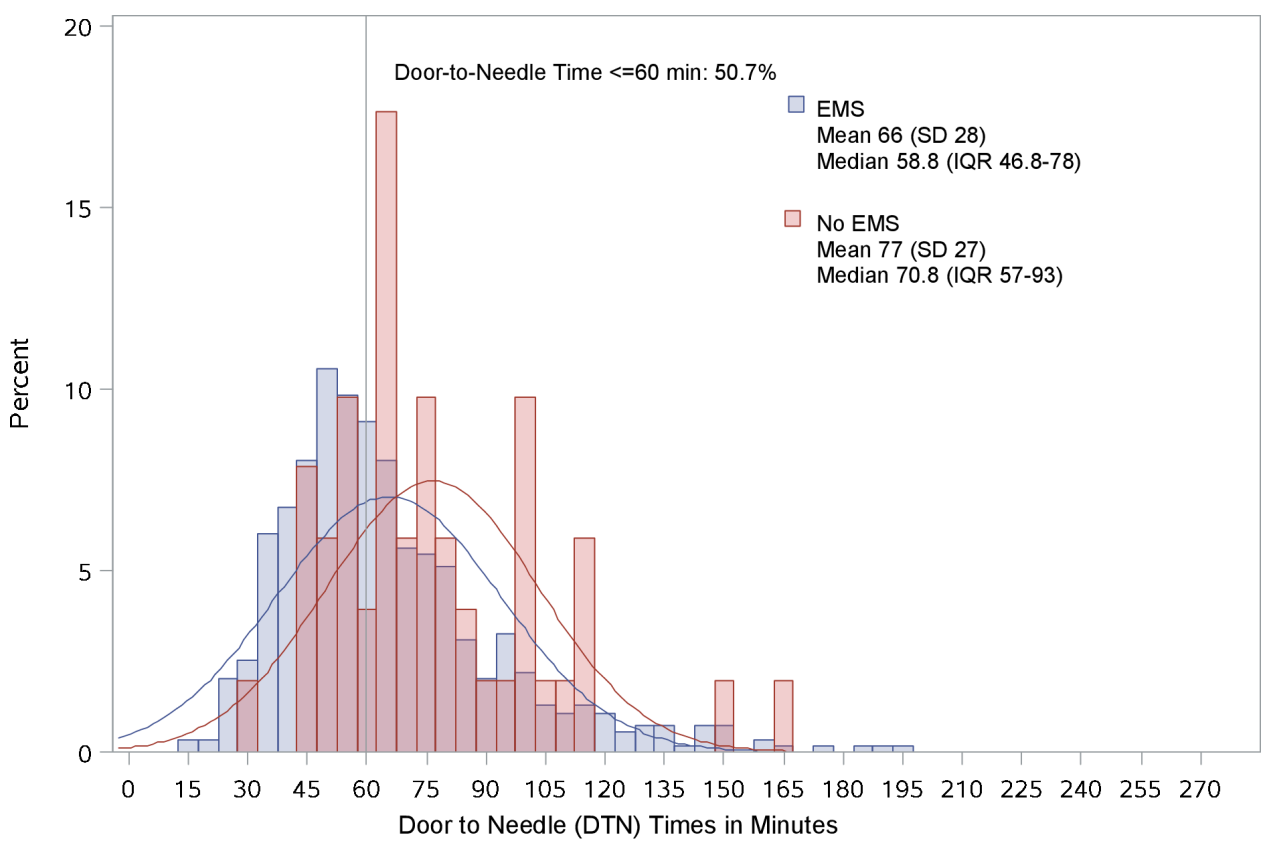

Figure 1 Distribution of door-to-needle (DTN) among patients receiving intravenous tissue-type plasminogen activator. EMS, emergency medical services.

may not be sufficient. More enhanced education may be needed for stroke patients before discharge to improve their understanding of the emergency nature of this disease.

Consistent with prior literature from western countries, ${ }^{6-11}$ our study suggests that EMS use was associated with rapid evaluation and treatment for acute ischaemic stroke in a large urban setting where tertiary care and stroke units are more available, and professional EMS services are easily accessible and coordinated with hospitals. Patients transported by EMS were more likely to receive tPA and were also more likely to receive the treatment faster. On average, among those who received tPA treatment, EMS-transported patients had an 11-min reduction in door-to-needle time. Prior research suggests that every minute reduction in the tPA administration can save nearly 2 million neurons, which translates into approximately 2 more days in healthy life. ${ }^{29} 30$ Therefore, this significant improvement in evaluation and treatment of acute ischaemic stroke has considerable clinical impacts on patient outcomes. Furthermore, increasing evidence has demonstrated the benefits of early endovascular thrombectomy for patients with ischaemic stroke due to intracranial large-vessel occlusions (LVO). ${ }^{31} 32$ Therefore, EMS use can potentially gain considerable treatment time for patients with LVO stroke. The current EMS system in Singapore implemented a stroke protocol that primarily focused on using CPSS to identify stroke patients who present early and might benefit from thrombolysis. ${ }^{17}$ Given that thrombectomy has become a critical component of stroke care, future research is needed to identify and implement strategies that increase the EMS capacity to recognise suspected LVO stroke cases in prehospital settings.

\section{Limitations}

We acknowledge several limitations of this study. First, the study was based on observational data, therefore, causality cannot be assessed. Furthermore, due to lack of information on stroke patients' socioeconomic status, we were unable to assess how other factors such as education, income, place of residence and health literary impact EMS use. ${ }^{33}$ Similarly, we lack information on the reason why some patients used EMS, whereas others did not. It is possible that patients who did not use EMS were due to failure in stroke symptom recognition. We also acknowledge that stroke patients with missing information on mode of transportation were excluded in the analyses, which may introduce potential bias to the study findings. We conducted exploratory analyses by coding these patients with missing information on transportation mode as self-transferred patients. The results were essentially the same as we presented in this study. Relatedly, due to data limitation, we were unable to differentiate patients who were transported by private ambulance from those transported by SCDF ambulance. Nevertheless, as we noted above, most stroke cases are transported by the national EMS system. Finally, the Singapore Stroke Registry only captured stroke patients who were Singapore citizens or permanent residents. Therefore, the study findings may not be generalisable to stroke patients who were foreigners.

\section{Conclusion}

In this study, more than one-third of acute ischaemic stroke patients in Singapore failed to activate EMS. Patients transported by EMS had significantly faster evaluation and a greater likelihood of receiving tPA treatment than those self-transported. Targeted public campaigns 
to advocate for stroke symptom recognition and appropriate EMS use are needed to enhance a seamless EMShospital stroke pathway.

\section{Author affiliations}

${ }^{1}$ Department of Family Medicine and Community Health, Duke University School of Medicine, Durham, North Carolina, United States

${ }^{2}$ Duke University School of Nursing, Durham, North Carolina, United States

${ }^{3}$ Duke Clinical Research Institute, Durham, North Carolina, United States

${ }^{4}$ Department of Neurology, Duke University School of Medicine, Durham, North Carolina, United States

${ }^{5}$ Department of Neurology, National Neuroscience Institute-Singapore General Hospital Campus, Singapore

${ }^{6}$ Department of Orthopaedic Surgery, Duke University School of Medicine, Durham, North Carolina, United States

${ }^{7}$ HomeTeam, Government of Singapore Ministry of Home Affairs, Singapore

${ }^{8}$ Department of Emergency Medicine, Singapore General Hospital, Singapore

${ }^{9}$ Program in Health Services and Systems Research, Duke-NUS Graduate Medical School, Singapore

${ }^{10}$ Department of Medicine (General Internal Medicine), Duke University School of Medicine, Durham, North Carolina, United States

Acknowledgements Special thanks to our colleagues from National Registry of Diseases Office for assistance with data management and analyses. An abstract resulted from this study was presented at the 5th European Stroke Organisation Conference on 22 May 2019.

Contributors $\mathrm{HX}$ and $\mathrm{YX}$ had full access to the data in the study and took responsibility for the accuracy of the data analysis. Study concept and design: HX. Acquisition of data: YX and FPW. Analysis and interpretation of data: HX, YX, JPB and DADS. Drafting of the manuscript: HX, YX and DADS. Critical revision of the manuscript for important intellectual content: JPB, DTL, YYN, MEHO, DBM and FPW. Statistical analysis: $\mathrm{HX}$ and YX. Administrative, technical or material support: FPW.

Funding This research was supported by a Duke/Duke-NUS Research Collaborations Pilot Project grant.

Competing interests None declared.

Patient consent for publication Not required.

Provenance and peer review Not commissioned; externally peer reviewed. Data availability statement Data may be obtained from a third party and are not publicly available. Data may be obtained from the National Registry of Diseases Office, Singapore, and are not publicly available.

Open access This is an open access article distributed in accordance with the Creative Commons Attribution Non Commercial (CC BY-NC 4.0) license, which permits others to distribute, remix, adapt, build upon this work non-commercially, and license their derivative works on different terms, provided the original work is properly cited, appropriate credit is given, any changes made indicated, and the use is non-commercial. See: http://creativecommons.org/licenses/by-nc/4.0/.

ORCID iD

Hanzhang Xu http://orcid.org/0000-0001-9617-247X

\section{REFERENCES}

1 Institute for Health Metrics and Evaluation. Global Burgen of disease profile: Singapore, 2017. Available: http://www.healthdata.org/ singapore

2 Venketasubramanian N, Chen CLH. Burden of stroke in Singapore. Int J Stroke 2008;3:51-4.

3 National Institute of Neurological Disorders and Stroke rt-PA Stroke Study Group. Tissue plasminogen activator for acute ischemic stroke. N Engl J Med 1995;333:1581-8.

4 Hacke W, Kaste M, Bluhmki E, et al. Thrombolysis with alteplase 3 to 4.5 hours after acute ischemic stroke. $N$ Engl $J$ Med 2008;359:1317-29.

5 Yng NY. Optimal use of emergency services. The Singapore Family Physician 2014;40:8-13.

6 Ekundayo OJ, Saver JL, Fonarow GC, et al. Patterns of emergency medical services use and its association with timely stroke treatment: findings from get with the Guidelines-Stroke. Circ Cardiovasc Qual Outcomes 2013;6:262-9.
7 EYM P, WM N, De Silva DA. Dedicated stroke nurse in stroke activation process improves Door-to-Needle time for intravenous thrombolysis in acute ischaemic stroke. Singapore Healthcare Management Singapore, 2017.

8 De Silva DA, Yassin N, Toh AJ, et al. Timing of arrival to a tertiary hospital after acute ischaemic Stroke-A follow-up survey 5 years later. Singapore: Annals Academy of Medicine, 2010: 39. 513.

9 Fassbender K, Balucani C, Walter S, et al. Streamlining of prehospital stroke management: the golden hour. Lancet Neurol 2013;12:585-96.

10 Lacy CR, Suh DC, Bueno M, et al. Delay in presentation and evaluation for acute stroke: stroke time Registry for outcomes knowledge and epidemiology (S.T.R.O.K.E.). Stroke 2001;32:63-9.

11 Lin CB, Peterson ED, Smith EE, et al. Emergency medical service Hospital prenotification is associated with improved evaluation and treatment of acute ischemic stroke. Circ Cardiovasc Qual Outcomes 2012;5:514-22.

12 Lin C-H, Ng YY, Chiang W-C, et al. Variation of current protocols for managing out-of-hospital cardiac arrest in prehospital settings among Asian countries. J Formos Med Assoc 2016;115:628-38.

13 Shin SD, Ong MEH, Tanaka H, et al. Comparison of emergency medical services systems across Pan-Asian countries: a web-based survey. Prehosp Emerg Care 2012;16:477-96.

14 Wah W, Pek PP, Ho AFW, et al. Symptom-to-door delay among patients with ST-segment elevation myocardial infarction in Singapore. Emerg Med Australas 2017;29:24-32.

15 Statistics SDo. Population and population structure, 2018. Available: https://www.singstat.gov.sg/find-data/search-by-theme/population/ population-and-population-structure/latest-data

16 The World Bank. Population density (people per SQ. Km of land area), 2017.

17 Singapore Civil Defence Force. SCDF emergency medical services, 2018. Available: https://www.scdf.gov.sg/home/about-us/ information/scdf-emergency-medical-services

18 Shah MN. The formation of the emergency medical services system. Am J Public Health 2006;96:414-23.

19 Kothari RU, Pancioli A, Liu T, et al. Cincinnati prehospital stroke scale: reproducibility and validity. Ann Emerg Med 1999;33:373-8.

20 National Registry of Diseases Office. Singapore stroke Registry. Available: https://www.nrdo.gov.sg/publications/stroke

21 Lim W, Chuang DF, Chue KM, et al. Stroke literacy in Singapore: data from a survey of public housing estate residents. Ann Acad Med Singapore 2014;43:454-63.

22 National Neuroscience Institute. Advanced neuroimaging increases acute treatment options for stroke, 2018. Available: https://www.nni. com.sg/news/patient-care/advanced-neuroimaging-increases-acutetreatment-options-for-stroke

23 Adeoye O, Lindsell C, Broderick J, et al. Emergency medical services use by stroke patients: a population-based study. Am J Emerg Med 2009;27:141-5

24 Hsieh M-J, Tang S-C, Chiang W-C, et al. Utilization of emergency medical service increases chance of thrombolytic therapy in patients with acute ischemic stroke. J Formos Med Assoc 2014;113:813-9.

25 Ho AFW, Loy EY, Pek PP, et al. Emergency medical services utilization among patients with ST-segment elevation myocardial infarction: observations from the Singapore myocardial infarction registry. Prehosp Emerg Care 2016;20:454-61.

26 Burn J, Dennis M, Bamford J, et al. Long-Term risk of recurrent stroke after a first-ever stroke. The Oxfordshire community stroke project. Stroke 1994;25:333-7.

27 Hankey GJ. Secondary prevention of recurrent stroke. Stroke 2005;36:218-21.

28 Lovett JK, Coull AJ, Rothwell PM. Early risk of recurrence by subtype of ischemic stroke in population-based incidence studies. Neurology 2004;62:569-73.

29 Meretoja A, Keshtkaran M, Saver JL, et al. Stroke thrombolysis: save a minute, save a day. Stroke 2014;45:1053-8.

30 Saver JL. Time is brain--quantified. Stroke 2006;37:263-6.

31 Jovin TG, Chamorro A, Cobo E, et al. Thrombectomy within 8 hours after symptom onset in ischemic stroke. N Engl J Med 2015;372:2296-306.

32 Saver JL, Goyal M, van der Lugt A, et al. Time to treatment with endovascular thrombectomy and outcomes from ischemic stroke: a meta-analysis. JAMA 2016;316:1279-89.

33 Kuek BJW, Li H, Yap S, et al. Characteristics of frequent users of emergency medical services in Singapore. Prehosp Emerg Care 2019;23:215-24.

34 Ong MEH, Ng FSP, Overton J, et al. Geographic-time distribution of ambulance calls in Singapore: utility of geographic information system in ambulance deployment (care 3). Ann Acad Med Singapore 2009;38:184-91. 